\author{
UNIVERSIDADE DE BRASÍLIA \\ CENTRO DE EXCELÊNCIA EM TURISMO \\ ESPECIALIZAÇÃO EM ECONOMIA DO TURISMO
}

MARINA CAMPEDELLI MARTENSEN

\title{
O ECOTURISMO COMO AGENTE TRANSFORMADOR DA GESTÃO ECONÔMICA E SOCIAL DOS PARQUES NACIONAIS DO BRASIL
}

BRASÍLIA

2006 
MARINA CAMPEDELLI MARTENSEN

\title{
O ECOTURISMO COMO AGENTE TRANSFORMADOR DA GESTÃO ECONÔMICA E SOCIAL DOS PARQUES NACIONAIS DO BRASIL
}

\author{
Trabalho apresentado como exigência parcial \\ para obtenção do certificado de conclusão de \\ curso de Pós-graduação lato sensu em \\ Economia do Turismo/centro de Excelencia \\ em Turismo - CET/UnB. \\ Orientador: Profo Dr. Jorge Nogueira Madeira.
}

BRASÍLIA - DSITRITO FEDERAL 
TERMO DE APROVAÇÃO

Centro de Excelência em Turismo

CURSO DE PÓS-GRADUAÇÃO LATO SENSU EM

Economia do Turismo

\title{
O ECOTURISMO COMO AGENTE TRANSFORMADOR DA GESTÃO ECONÔMICA E SOCIAL DOS PARQUES NACIONAIS DO BRASIL
}

\author{
MONOGRAFIA PARA OBTENÇÃO DO CERTIFICADO DE CONCLUSÃO DO \\ CURSO DE PÓS-GRADUAÇÃO LATO SENSU
}

Aluno: Marina Campedelli Martensen

Orientador: Prof ${ }^{0}$ Dr. Jorge Nogueira Madeira

Examinador: Profo Dr. Roberto Ellery Júnior

Coordenador: Prof ${ }^{\circ}$ Dr. Maria de Lourdes Mello

Brasília, Setembro de 2006. 


\section{DEDICATÓRIA}

Aos meus pais

Que jamais deixaram de me incentivar e que sempre souberam que a única forma de conhecer é descobrir, e que fazer descobrir é a única forma de ensinar. 


\section{AGRADECIMENTOS}

A realização deste trabalho só foi possível graças à colaboração direta ou indireta de muitas pessoas. Manifesto minha gratidão a todas elas e de forma particular:

Aos colegas da Pós Graduação Rodrigo e Paula, que sempre estiveram presentes;

Aos Profs. Drs. Jorge Madeira Nogueira e Maria de Lourdes Mello pela orientação, colaboração e amizade;

E em especial a meus pais e irmãos que sempre me apoiaram, incentivaram e mais ainda, acreditaram na minha causa, muito obrigada.

Ao meu namorado, Marcelo, que me apoiou e sempre esteve ao meu lado em todos os momentos.

E ao meu amado sobrinho Théo, que sempre me deixou feliz e entusiasmada pela vida e pela preservação de uma natureza que lhe garantirá um futuro feliz. 


\section{EPÍGRAFE}

"O que sabemos é uma gota. O que ignoramos é um oceano".

Isaac Newton (1643-1727) 


\section{LISTA DE GRÁFICOS}

Gráfico 1 - Preços de impressos adequados para estrangeiros: opiniões colhidas em três parques da

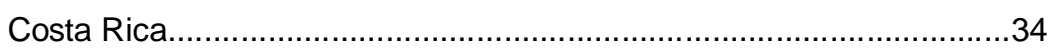

Gráfico 2 - Diagnóstico da Visitação em Parques Nacionais e Estaduais.....................41 


\section{LISTA DE TABELAS}

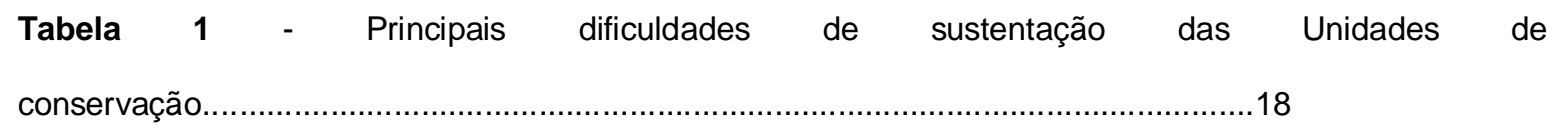

Tabela 2 - Aspectos Ambientais Positivos e Negativos do Ecoturismo.................22

Tabela 3 - Aspectos Econômicos Positivos e Negativos do Ecoturismo.................22

Tabela 4 - Tipos de Taxas e Encargos em Áreas Protegidas..............................30

Tabela 5 - Taxas de Entrada do Parque Nacional de Galápagos, no Equador...........32

Tabela 6 - Tipos de Taxas e Encargos em Áreas Protegidas.................................42 


\section{APÊNDICE}

PROJETO E ESTUDO SOBRE ECONOMIA E TURISMO SUSTENTAVEL DESENVOLVIDO PELO OBSERVATÓRIO PARA O TURISMO SUSTENTÁVEL DA

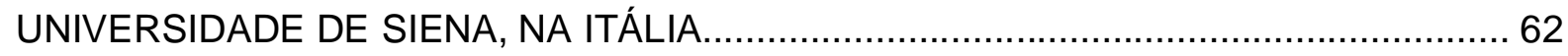




\section{RESUMO}

A presente monografia aborda a importância do ecoturismo como agente transformador da gestão econômica e social de Parques Nacionais. Analisa alternativas de sustentabilidade e rentabilidade econômica para as Unidades de Conservação, por meio de ferramentas para a geração de receita para a unidade e comunidade do entorno. Este estudo analisa a importância econômica de um PN, desde suas riquezas naturais, seu desenvolvimento sócio econômico, até as dificuldades de financiamento para a conservação e preservação do seu ecossistema. Desta maneira discutem-se alternativas e experiências bem sucedidas na gestão do ecoturismo em PN, favorecendo ferramentas de autofinanciamento, como taxas de arrecadação e desenvolvimento sustentável. Analisando os pontos positivos existentes em Parques Nacionais estrangeiros e no Parque Nacional do Iguaçu, especialmente no que se refere às principais finalidades sociais e formas de obtenção dos recursos financeiros. Averigua, também, pesquisas e práticas de turismo sustentável adotadas na Itália, observadas através de algumas bibliografias disponíveis sobre o assunto. Uma alternativa proposta neste trabalho é a implementação de ferramentas rentáveis para auxiliarem a gestão econômica e social do ecoturismo em Parques Nacionais Brasileiros.

\section{Palavras-chave: Parque Nacional, Sustentabilidade Econômica e Ecoturismo.}




\begin{abstract}
The present monograph focuses the importance of Eco-tourism as a transforming activity for the financial and social management of National Parks. It analizes alternatives to financial sustainability and profitability for Preservation Units by means of options for generation of income for the unit and its natural resources, its socio-economical development and also for managing difficulties in providing money resources for the maintenance and preservation of its ecosystem. Here we debate alternatives and successful experiments in the management of Eco-tourism in National Parks, specially focusing self-financing practice such as the charging of fees and sustainable development. Positive aspects concerning management systems in foreign national parks and in "Parque Nacional do Iguaçú" ( National Park of Iguazu) specially referring to social aims and ways for providing financial resources are also discussed here. Research and the practice of sustainable tourism in use in Italy have also been studied from some available bibliography on the subject. The purpose of this paper is the carrying out of the implement of profitable tools to aid socio-economical management in Brazilian National Parks.
\end{abstract}

Key-Words: National Park, Economical Sustainability and Ecotourism. 


\section{SUMÁRIO}

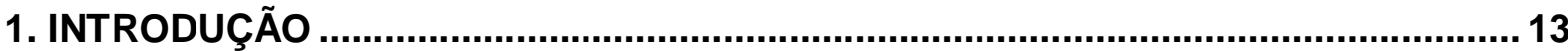

2. A IMPORTÂNCIA DOS PARQUES NACIONAIS ..................................................... 16

2.1 - A RIQUEZA CONSERVADA NOS PARNAS................................................................ 16

2.2 - O DESENVOLVIMENTO SUSTENTÁVEL, A ECONOMIA E SEU BENEFÍCIO PARA

PARQUES NACIONAIS.

2.3 - A IMPORTÂNCIA ECONÔMICA DE UM PARQUE NACIONAL ........................................ 23

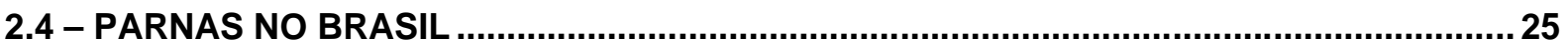

2.5 - AS DIFICULDADES DE FINANCIAMENTO DOS PARQUES .......................................... 27

3. ECOTURISMO COMO ALTERNATIVA ECONÔMICA PARA GESTÃO DE PARQUES NACIONAIS.

3.1 - ECOTURISMO: SUA IMPORTÂNCIA ECONÔMICA, SOCIAL, AMBIENTAL E SUA RELAÇÃO COM O DESENVOLVIMENTO ECONOMICO E SOCIAL DE UM PAÍS. 30

3.2 - O PAPEL DO ECOTURISMO EM PARQUES NACIONAIS

4. INSTRUMENTOS DE GESTÃO PARA O ECOTURISMO EM PARQUES NACIONAIS

4.1 INSTRUMENTOS DE GESTÃO RELATIVOS À VISITAÇÃO E CONSERVAÇÃO.

4.2 - ECOTURISMO EM PARQUES: UMA AVALIAÇÃO ECONÔMICA DE CASOS BRASILEIROS

5. CONSIDERAÇÕES FINAIS APÊNDICE: PROJETO E ESTUDO SOBRE ECONOMIA E TURISMO SUSTENTAVEL DESENVOLVIDO PELO OBSERVATÓRIO PARA O TURISMO SUSTENTÁVEL DA UNIVERSIDADE DE SIENA, NA ITÁLIA. 


\section{INTRODUÇÃO}

Um dos mecanismos mais tradicionais utilizados no mundo para a conservação da biodiversidade é a implantação das Unidades de Conservação (UC's). As UC's surgiram como uma proposta maior de conservação do ecossistema, objetivando melhorar as condições ambientais dessas áreas e, assim, assegurar uma solução para ameaças locais à biodiversidade.

As áreas naturais protegidas apresentam-se enquadradas em sistemas que possuem características variadas nos diversos países. O grande marco histórico da proteção de ambientes naturais, com a iniciativa de luta pela conservação, foi em 1872 com a aprovação pelo Congresso Americano da ata de criação do "Parque Nacional de Yellowstone", nos Estados Unidos (COSTA, 2002). Segundo Salgado (2000), naquela época a fundamentação para a existência desse tipo de área era a socialização e o usufruto das belezas cênicas pela população. Já no Brasil, o marco inicial para o estabelecimento de um sistema nacional de áreas protegidas foi a criação, em 1937, do Parque Nacional de Itatiaia pelo político e engenheiro brasileiro André Rebouças, com o objetivo de preservar e conservar ecossistemas com uma grande importância ecológica, cênica, cientifica, cultural, educativa e recreativa (COSTA, 2002).

As UC's possuem uma fauna e flora das mais exuberantes do mundo. Os atrativos naturais oferecidos pelos Parques Nacionais se tornaram uma grande potencialidade para a prática do ecoturismo, o lazer e atividades de educação ambiental. A conservação da biodiversidade e a realização do turismo sustentável permitiram que cientistas, estudantes, educadores e a comunidade em geral encontrassem material para suas pesquisas e satisfação de diversas necessidades. Assim a idéia de criar áreas para preservar a diversidade biológica e promover o ecoturismo acompanhou uma tendência mundial, que via nas áreas protegidas a principal estratégia para o desenvolvimento sustentável de uma área. (SALGADO, 2000).

De acordo com Salgado (2000), com freqüência as UC's são instituições que podem gerar receitas significativas. Contribuindo assim para as economias locais, com a geração de emprego e renda. O beneficio de investimentos 
em Parques Nacionais pode ser expressivo para as economias locais, nacionais e principalmente para sustentar a rentabilidade do Parque.

Os principais atrativos ofertados pelos Parques Nacionais são produtos e serviços ligados ao ecoturismo. Estes são considerados dos poucos fatores capazes de promover a sustentabilidade de uma região de forma eficaz, porque não apenas ajudam a preservar áreas selvagens, mas geram também retorno econômico a partir de terras postas de lado para conservação (VAN SCHAIK, et al 2002).

Para que as áreas protegidas continuem sendo preservadas e conservadas, o ecoturismo deve ser operado por profissionais especializados, sem que se diminua ou aumente o valor respectivo do atrativo. A renda gerada pode ser utilizada para a manutenção da área protegida. Alternativas inovadoras em relação às fontes tradicionais de manutenção das áreas protegidas são necessárias, principalmente para assegurar a sua viabilidade e existência em longo prazo.

O objetivo da presente monografia é identificar ferramentas financeiras de manejo que auxiliem no planejamento e na promoção do ecoturismo dentro dos Parques Nacionais. Essas ferramentas desempenham papel básico na garantia de encontrar formas rentáveis para sua manutenção, conservação e socialização com a comunidade em seu entorno.

Nesse contexto, a monografia demonstra alternativas de sustentabilidade e rentabilidade econômica por meio de instrumentos de gestão, avaliando a situação administrativa e financeira de Parques Nacionais, para responder a questões como: os Parques Nacionais Brasileiros são rentáveis? Os recursos financeiros fornecidos às UC's seriam suficientes para a sustentabilidade da unidade? Que outros tipos de arrecadação os Parques poderiam receber, considerando-se que são - Unidades de Proteção Integral - e que, portanto, não podem arrecadar fundos a partir da utilização sustentável de seus recursos naturais? O ecoturismo é uma alternativa de sustentabilidade sócio econômica? E quais são seus impactos, positivos e negativos?

Para a obtenção das informações utilizadas nesta monografia foi realizada uma pesquisa bibliográfica e documental, que permitiu conhecer o que já foi estudado sobre o tema, as abordagens adotadas, as hipóteses já exploradas e as por explorar, os problemas não resolvidos ou solucionados parcial ou satisfatoriamente. 
A monografia está composta por cinco capítulos, incluindo esta Introdução e Considerações Finais. No segundo capítulo aborda-se a importância econômica de um Parque Nacional (PARNA). Neste item analisa-se a conservação in-situ via Unidades de Conservação, mostrando a riqueza dos PARNAS, o desenvolvimento sustentável como alternativa para reduzir a perda da diversidade biológica nessas áreas, a inserção da comunidade local e também as dificuldades de financiamento para gestão produtiva e rentável dos Parques Nacionais. O terceiro capítulo tem como foco o ecoturismo, apresentando seu conceito e suas características, relacionando a sua importância econômica e social nos Parques Nacionais e o seu papel na economia do turismo. O quarto capítulo mostrará instrumentos e alternativas de gestão econômica e social para Parques Nacionais. Ainda neste capítulo será abordada uma avaliação econômica de Parques brasileiros e um breve estudo sobre uma experiência bem sucedida de um observatório de turismo na Itália. No quinto capitulo serão feitas considerações finais sobre essa revisão bibliográfica. 


\section{A IMPORTÂNCIA DOS PARQUES NACIONAIS}

\section{1 - A RIQUEZA CONSERVADA NOS PARNAS}

O conceito "parque" surgiu na Europa Medieval, que designava áreas da natureza nas quais animais viviam sob responsabilidade do rei. Essas áreas eram protegidas, e se alguém as invadissem para caçar ou mesmo aventurarse sem permissão era condenado à morte. Apesar desses relatos mais antigos o conceito Parque Nacional surgiu apenas no século XIX nos Estados Unidos com a criação do Parque Nacional de Yellowstone em 1872. A partir desta data até 1994, já foram criados mais de 8.500 áreas protegidas em todo o mundo (RUNTE, 1979 apud MORSELLO, 2001). Conforme Salgado (2002, p.6),

\footnotetext{
"em 1985 existiam cerca de 3.500 sítios protegidos, distribuídos em 136 países, cobrindo cerca de 423 milhões de hectares. Já em 1992, a quantidade de áreas protegidas em todo o mundo subiu para aproximadamente 8.000 sítios, abrangendo um território de quase 750 milhões de hectares, e representando $5,1 \%$ dos ecossistemas terrestres. Em 1997, as áreas protegidas já somavam mais de 30.000 unidades, envolvendo uma parcela do globo terrestre de cerca de 13,2 milhões de $\mathrm{km}^{2}$.
}

$\mathrm{Na}$ América do Sul os parques surgiram pelo esforço de um pequeno grupo de pessoas como Henri Piter da Venezuela, Francisco P. Moreno da Argentina, dentre outros, que argumentavam aos políticos sobre a grande necessidade da criação dos parques para a proteção das florestas como fim de evitar erosões, enchentes, variações extremas de temperaturas, elementos bastante fortes e idealistas para o governo aferir. Em 1948 foi criada então a União Internacional para a Proteção da Natureza, com o objetivo de obter uma cooperação internacional e integração entre áreas protegidas, que após algumas transformações, em 1965, originou a União Internacional para a Conservação da Natureza (IUCN) (MORSELLO, 2001).

Os Parques Nacionais são unidades de conservação e proteção integral por abrigarem áreas naturais com características de grande relevância sob os aspectos ecológicos de beleza cênica, científico, cultural, educativo e recreativo. Não são permitidas alterações na dotação de bens ambientais dentro dos seus 
limites, à exceção de medidas de recuperação e preservação do equilíbrio natural ( MMA, 2000).

Cada unidade deve possuir um plano de manejo que regulamente $o$ seu funcionamento e atividades permitidas, tais como a visitação pública com fins educacionais, científicos ou recreativos. A regulamentação estende-se também às pesquisas científicas, que devem ser precedidas de autorização do órgão responsável pela sua administração, bem como estar sujeitas às condições e restrições por ele determinadas.

O grande valor econômico das áreas protegidas é o seu ecossistema. As medidas de conservação e o manejo nas UC's levantam a questão sobre a preservação da biodiversidade, com a necessidade de se adequar à promoção do desenvolvimento econômico e social sem que haja comprometimento dos recursos naturais. De acordo com Constance (2000 ,p.19),

\begin{abstract}
"enquanto a preservação consiste na política de se deixar um ecossistema intocado pelo homem, a conservação, que pode ser feita in-situ ou ex-situ, é um mecanismo mais próximo à realidade, por meio da qual se busca manter as características essenciais das espécies ou do hábitat natural, permitindo que uma parte do recurso seja desenvolvido e utilizado para fins comerciais, culturais, turísticos e recreativos".
\end{abstract}

\title{
2.1.1 Conservação in situ
}

Conforme 0 art. $2^{\circ}$ da Convenção sobre Diversidade Biológica (CDB), citado em Primack e Rodrigues (2001, p. 199), a conservação in-situ é

\footnotetext{
"a conservação de ecossistemas e habitat naturais e a manutenção e recuperação de populações viáveis de espécies em seus meios naturais e, no caso de espécies domesticadas ou cultivadas, nos meios onde tenham desenvolvido suas propriedades características".
}

A conservação in-situ é realizada por meio da reserva de áreas protegidas, pela restauração de habitats degradados ou fatores que incentivem a conservação em espaços fora das áreas protegidas. Esta prática é designada, regulada e administrada geograficamente para obter objetivos específicos de conservação . Essas áreas protegidas devem ser destinadas para conservação de 
ecossistemas considerados relevantes, tanto em função da biodiversidade existente quanto da presença de espécies endêmicas ou ameaçadas (CDB, art. $2^{\circ}$ ).

De acordo com Primack e Rodrigues (2001, p. 224 apud CONSTANCE 2003) os valores culturais associados ao sítio ou aos recursos naturais existentes nessas áreas de proteção têm um maior grau de conservação e tendem a ser obtidas em áreas contíguas, de baixa densidade populacional e pouco exploradas pelo homem.

Segundo Albagli (1998), o estabelecimento de áreas protegidas recai em inúmeras controvérsias. A escolha do local é uma das tarefas mais delicadas, podendo trazer conflitos com os interesses das populações locais. De forma a garantir a manutenção dessas áreas, recomendam que haja sempre espaço para a participação das populações locais, com vistas a integrar suas necessidades imediatas aos objetivos da conservação.

Conforme observa Salgado (2000), a participação da população local nos benefícios da conservação vem sendo considerada como uma das condições para a solução de conflitos na gestão das áreas de conservação. No entanto, o autor avalia que essa inclusão costuma ser ignorada no desenho e aplicação dos projetos de conservação, em parte devido ao receio de que se revelem interesses conflitantes entre os habitantes locais, de um lado, e organismos governamentais ou não-governamentais, de outro.

Nos Parques Nacionais, os recursos naturais são preservados para uso futuro de forma compatível com as políticas nacionais. As áreas de manejo de uso múltiplo visam a utilização sustentável dos recursos naturais em atividades como pastagem, extração de madeira, turismo, caça, pesca, entre outras (PRIMACK e RODRIGUES, 2002).

Assim seria ideal que a Unidade inserisse a comunidade nos planejamentos sócio-econômicos da região, para estabelecer um processo participativo entre as UC's, seus vizinhos e a sociedade em geral, para, se necessário indenizar a população pelo não uso temporário dos recursos, como no caso da pesca em fase da desova. 


\subsubsection{Conservação ex situ}

A CDB, em seu art. $2^{\circ}$, define a conservação ex situ como a "conservação de componentes da diversidade biológica fora de seus habitats naturais". A conservação pode ser realizada em zoológicos, jardins botânicos, aquários, criações em cativeiro, coleções de microrganismos e bancos de sementes, dentre outros (ALBAGLI, 1998).

A conservação ex situ é contemplada pela CDB com o objetivo de complementar a conservação in situ, podendo ser eficaz na proteção de espécies ameaçadas que tenham sido deslocadas do seu habitat natural. A CDB recomenda que a conservação ocorra preferencialmente no país de origem dos recursos biológicos. Entretanto, os países em desenvolvimento têm apresentado dificuldades para manter coleções ex situ, em vista de seus elevados custos. No Brasil, por exemplo, as espécies nativas são sub-representadas e a falta de recursos implica na descontinuidade e abandono dessas coleções (ALBAGLI, 1998).

\section{2 - O DESENVOLVIMENTO SUSTENTÁVEL, A ECONOMIA E SEU BENEFÍCIO} PARA PARQUES NACIONAIS.

O conceito de sustentabilidade, cuja origem remete às relações entre os seres humanos e o meio ambiente, aponta quatro domínios nos quais deve ser garantido o desenvolvimento: o econômico, político, social e cultural. A viabilidade econômica depende de um uso de recursos que não os esgote irreversivelmente, e de um padrão de manejo resultante de produção que não destrua a vida. Faria (2002, pg. 34) afirma que: 
"A sustentabilidade é uma relação entre sistemas econômicos dinâmicos e sistemas ecológicos maiores, também dinâmicos e que, no entanto, modificam-se mais lentamente, de tal forma que a vida humana pode continuar indefinidamente, os indivíduos podem prosperar e as culturas humanas podem desenvolver-se, mas também, uma relação no qual efeitos das atividades humanas permanecem dentro de limites que não deterioram a saúde e integridade de sistemas auto-organizados que fornecem contexto ambiental para as atividades".

A sustentabilidade política se baseia em dar a todos os membros da sociedade uma responsabilidade em sua sobrevivência. $E$ por fim se 0 desenvolvimento é para ser social e culturalmente sustentável, os fundamentos da vida comunitária e os sistemas simbólicos de significação devem ser protegidos e conservados. O antagonismo entre crescimento econômico e sustentabilidade, é próprio de uma sociedade capitalista, na qual a preocupação em garantir a continuidade do processo de industrialização, afetada pelo esgotamento de recursos, esbarra em uma lógica de mercado, alheia a estratégias a médio e longo prazo que priorizam benefícios sociais e ambientais em oposição à acumulação de renda e conseqüentes disparidades econômicas.

Em geral, economia e ecologia são tratadas como dois sistemas distintos, porém na ótica da sustentabilidade é imprescindível que sejam tratadas como partes da estrutura de um único e mesmo sistema. Foi neste sentido que surgiu a área de "Economia-Ecológica". Os fatores econômicos e ecológicos de um sistema operam em escalas, tempos e espaços diferentes. Não é por acaso que interesses econômicos de curto prazo chocam-se com interesses ecológicos de longo prazo. O problema da sustentabilidade dos sistemas é como fazer com que os "feedbacks" ecológicos sejam menores, de modo a incorporá-los a sistemas econômicos e sociais (FARIA, 2002).

Conforme Pires (2004, p. 44), para que o planejamento turístico possa possibilitar seu desenvolvimento sustentável, deve conter, segundo a Organização Mundial de Turismo - OMT os seguintes fatores: a Sustentabilidade Econômica, em que se inclui a maximização da utilização dos recursos naturais, com redução dos custos ambientais; a Sustentabilidade Social que prevê a 
adaptabilidade e a capacitação social; a Sustentabilidade Ambiental onde se analisa os níveis de visitação, os tipos de visitantes e seu comportamento; a Sustentabilidade Cultural envolvendo um estudo sobre a singularidade, a força e a capacidade cultural; e por fim a Sustentabilidade Política que é determinada pelo apoio e pelo envolvimento da população local e governantes no destino turístico. Estes conjuntos de fatores compõem o almejado turismo sustentável e necessitam serem previstos dentro da elaboração de projetos e planos, de forma que todos sejam contemplados e estejam em equilíbrio entre si.

Assim, o Desenvolvimento Sustentável não é um processo constante de harmonia, e sim um processo mutante no qual envolve a exploração dos recursos naturais, a direção dos investimentos, o desenvolvimento tecnológico e econômico. A conservação e as mudanças institucionais caminham de acordo com as necessidades atuais e futuras dessas áreas protegidas. Essa idéia fundamenta os conceitos de uma sociedade e seu crescimento econômico norteado pela questão ecológica.

O Desenvolvimento Sustentável nos remete à capacidade de progredir sem agressão ou dano aos recursos utilizados, trazendo benefícios a ambas as partes envolvidas, o homem e o meio (COSTA, 2002). Assim, em Parques ele visa uma abertura para que as populações locais utilizem os recursos naturais da área de uma forma consciente sobre o seu ecossistema (TERBORGH e VAN SCAIK, 2002). Somente permitindo que a comunidade possa viver dos recursos destes Parques de forma sustentável que se é possível promover a preservação de fato.

Segundo Kinker (2002) os benefícios que os Parques Nacionais trazem para a sociedade são inúmeros, quando bem estruturados e ligados à conservação da biodiversidade, com oportunidades de geração de emprego, renda, educação e recreação. A comunidade deve ser estimulada a participar do planejamento sustentável da localidade, não só por ser um direito básico, mas também porque é uma peça-chave para concretizar o Desenvolvimento Sustentável. Assim: 
"o processo de aproximação concreta entre os administradores e gestores de áreas protegidas, a comunidade local e os ambientalistas deve ser implementado, minimizando-se o conflito existente de que conservação é incompatível com o desenvolvimento" (SALGADO, 2002, pg 15).

Ao se criar uma área protegida, geralmente as medidas tomadas para a sua implantação são restritivas em relação ao uso dos recursos existentes pela comunidade local. $\mathrm{O}$ desenvolvimento de projetos alternativos e medidas de compensação para a geração de renda da população local diante da criação da UC, se fazem necessário para minimizar muitas vezes a perda econômica da comunidade, que estava acostumada a obter renda, na área agora protegida (MOTTA, 2005, p. 24).

Segundo Ferreti (2002, p.118).

“ o turismo sustentável só será viável se o poder de conservação dos lugares turísticos essenciais forem administrados e, em seguida, implantados rigorosamente por meio de um sistema eficiente de controles de operação e planejamento. (...) O Turismo sustentável também requer a aprovação de conceitos de validade e cooperação em sua implantação pelo setor turístico privado, além da participação das comunidades locais e dos próprios turistas".

O Desenvolvimento Sustentável tem como foco preservar a natureza promovendo não só a sustentabilidade ambiental, mas também o desenvolvimento sócio-econômico da região, integrando a população local no desenvolvimento e possibilitando oportunidades de integração entre ambas. Não adianta somente contornar a agressão ambiental, como alternativa para a obtenção de desenvolvimento sócio-econômico, mas sim oferecer alternativas para o envolvimento da relação parque-comunidade (SALGADO, 2002).

No contexto do desenvolvimento sócio-econômico, neste trabalho também será abordado a Experiência do Observatório em Turismo na Itália como ferramenta eficaz para o desenvolvimento local, em que a comunidade do entorno trabalha e se compromete com o turismo local. 


\section{3 - A IMPORTÃNCIA ECONÔMICA DE UM PARQUE NACIONAL}

A importância econômica de um Parque Nacional decorre da preocupação mundial com a preservação e conservação dos recursos naturais. Essa preocupação surge do modo como atividades, que geram bens e serviços que se utilizam dos recursos ambientais, vem ocorrendo de forma desordenada; e do aumento da demanda por estes bens, que muitas vezes acarretam uma enorme perda de bem-estar na quantidade e na qualidade dos serviços oferecidos. Os valores econômicos de uma área protegida são seus custos e benefícios, atribuídos aos valores dos bens e serviços promovido pelo meio ambiente, (BRAGA,2004).

Assim, ao identificar os bens, serviços ou produtos que as áreas protegidas oferecem, e que são adequados para a obtenção de renda para as mesmas, estes devem ser estruturados por uma administração apropriada, para que o produto em "oferta" possa ser comercializado continuamente sem que se diminua o valor respectivo, gerando renda para a manutenção da área protegida.

Embora os serviços gerados pelos Parques Nacionais, como o ecoturismo, educação ambiental, hospedagem e outros de natureza ambiental, sejam importantes para a sociedade, como já destacado, seus mercados tendem a ser precários ou inexistentes, fazendo com que os preços praticados não reflitam seu real valor e não promovam adequadamente um equilíbrio entre custos e benefícios.

De acordo com Morsello (2001) existem três grandes problemas econômicos relacionados às áreas protegidas. $O$ primeiro se refere à falta de reconhecimento integral dos benefícios que as UC's proporcionam à sociedade, o segundo o ceticismo da sociedade quanto ao valor desses benefícios e, por fim, a crença que os investimentos no manejo de áreas protegidas somente terão resultados se for acompanhados por políticas mais amplas de desenvolvimento, que procurem aprimorar as distorções existentes atualmente. Para Salgado (2002, pg. 12-13), 
"os maiores desafios de gestão em áreas protegidas são primariamente de cunho ecológico, e não socioeconômico e político; assim, os administradores consideram seus problemas administrativos sob uma visão estreita, meramente preservacionista, tentando isolar a área do ambiente em que ela se insere, e não tendo uma visão mais ampla, envolvendo as áreas adjacentes e a sociedade local, entre outros setores".

Há pouco tempo atrás, na década de 90, os parques eram vistos como limitadores de oportunidade de desenvolvimento econômico e a criação deles era ativamente combatida por madeireiros, mineradores e proprietários de terra (TERBORGH, 2002; VAN SCHAIK, 2002). As áreas protegidas eram e, ainda em muitas localidades, são vistas como algo isolado do desenvolvimento econômico do país, uma percepção equivocada, pois as UC's podem contribuir muito para o desenvolvimento ambiental de uma localidade, através da conservação ou exploração sustentável de recursos naturais, de atividades produtivas como na geração de emprego e renda para a população que nela reside (MORSELLO, 2001).

Atualmente, no entanto, o aumento das áreas protegidas, sobretudo aquelas para fins recreativos é bem significativo, e os resultados gerados pelo "desenvolvimento sustentável", fundamentado no ecoturismo nessas áreas protegidas, têm trazido benefícios em muitas localidades (VAN SCHAIK, 2002).

De acordo com dados da IUCN (1998), no Canadá o governo arrecada cerca de 6,5 bilhões de dólares canadenses, para o Produto Interno Bruto, com lucro adquirido em atividades turísticas relacionadas com áreas protegidas, além de criar 159.000 postos de trabalho. A Austrália arrecada mais de 2 bilhões de dólares australianos na gestão de oito parques nacionais, com custos governamentais de cerca de 60 milhões de dólares. Na Costa Rica, em 1991 aproximadamente 12 milhões de dólares foram gastos na manutenção dos parques nacionais, contra uma receita de 330 milhões de dólares, provinda do lucro de 500.000 visitantes, sendo o turismo gerado a partir dos parques a segunda maior fonte de arrecadação do país. Conforme Van Schaik (2002, p. 30), 
"os parques bem sucedidos não são meramente conseqüência de disponibilidade financeira. Alguns paises relativamente pobres têm sido capazes de manter parques com pouca ajuda externa, enquanto alguns mais prósperos têm falhado visivelmente. Os principais componentes do sucesso, talvez os cruciais, têm sido a postura e a força das instituições locais".

Fica cada vez mais claro que o desenvolvimento ecoturistíco das UCs, depende da maturidade dos administradores em visualizar um planejamento baseado na sustentabilidade econômica, ambiental e social da unidade e seu entorno, criando possibilidades de empregabilidade, por meio, da sua grande riqueza conservada, o atrativo natural.

\section{4 - PARNAS NO BRASIL}

O Brasil é reconhecido como um dos celeiros da biodiversidade mundial. $\mathrm{Na}$ busca da preservação desta riqueza biológica algumas iniciativas foram adotadas, contemplando, além da conservação, a possibilidade de pesquisa científica, a educação ambiental e o lazer. Uma dessas iniciativas é a criação e implementação das chamadas Unidades de Conservação (UCs), pelo Instituto Brasileiro do Meio Ambiente e dos Recursos Naturais Renováveis (IBAMA). Tais Unidades fazem parte do Sistema Nacional de Unidades de Conservação (SNUC), cujo objetivo é delimitar áreas de proteção integral de fauna, flora e belezas naturais, as reservas particulares do patrimônio nacional, as reservas ecológicas e os parques nacionais.

O Brasil possui a maior diversidade de espécies do mundo, com uma área de cerca de 9 milhões de $\mathrm{km} 2$. O país hoje possui um número relativamente extenso de unidades de conservação, com cerca de 1.000 unidades de conservação e reservas particulares, federais e estaduais, totalizando aproximadamente 70 milhões de hectares. Esse dado implica em que, teoricamente, $8 \%$ do território nacional estejam hoje sob alguma forma de proteção oficial (MMA, 1998). Considerando somente as unidades de conservação de uso indireto, que em virtude das restrições de uso constituem-se naquelas de maior relevância para a 
conservação da biodiversidade, menos de 3\% (cerca de 22 milhões de hectares) da superfície do território brasileiro se encontra dedicado oficialmente a esse objetivo. No Brasil,

"embora não existam estimativas exatas, o somatório das áreas protegidas em nível federal esta por volta de 3,7\% da superfície do país, bastante abaixo da média latino-americana de $6 \%$. Em virtude disso, o Brasil ocupa o décimo terceiro lugar em superfície protegida dentre os países da região" (MORSELLO, 2001,p. 45-46).

A história dos Parques Nacionais brasileiros teve inicio quando, inspirado na criação do Parque de Yellowstone, o político e engenheiro André Rebouças propõe, em 1876, a criação de Parques Nacionais nas áreas de Sete Quedas, da llha do Bananal e dos rios Tocantins e Araguaia. Porém, somente em 1937 foi criado o primeiro Parque Nacional, o de Itatiaia, no Rio de Janeiro, com finalidades de caráter científico e turístico. Depois deste Parque pioneiro, foram criados os Parques Nacionais de Iguaçu, no Paraná, e o da Serra dos Órgãos, no Rio de Janeiro, em 1939 (PIRES, 2004).

Mesmo com grande número de UC's no território brasileiro, elas não vêm sendo um instrumento eficaz na conservação da biodiversidade, e a causa para essa ineficácia é o numero insuficiente de áreas para a proteção integral do bioma, dadas as grandes dimensões do território e a diversidade de ecossistemas encontrados no país.

Os Parques Nacionais no Brasil têm como objetivo a preservação e conservação para alcançar o equilíbrio da sua biodiversidade natural. Porém, a gestão dos Parques isola as áreas protegidas da influência humana e do contexto social e econômico que os rodeiam. Com isso geram conflitos sociais, principalmente das comunidades do entorno, que muitas vezes dependem economicamente, por residirem ou tirarem subsistência dessas áreas anteriormente, e acabam por dificultar os projetos e idéias de desenvolvimento sustentável, pois estas pessoas se excluem do envolvimento com a UCs (SALGADO, 2000).

No Brasil, existem projetos que têm por objetivo reduzir as ameaças externas aos parques, promovendo desenvolvimento sustentável nas áreas do entorno. A idéia dos Projetos Integrados de Conservação e Desenvolvimento ICDPs é de que financiando projetos na comunidade rural, seriam trazidos 
benefícios para a conservação da natureza e desenvolvimento econômico (VAN SCHAIK \& RIJKSEN, 2002).

As conseqüências, porém, negativas para a conservação das áreas protegidas podem ser ainda piores no caso de projetos mal estruturados. Geralmente, alguns projetos têm uma natureza mais técnica do que políticoadministrativa, apresentando a desvantagem de possuírem soluções de manejo de curta duração, comprometendo, muitas vezes, a negociação de financiamentos seguros para a manutenção adequada das áreas de proteção, como veremos no capitulo seguinte (MOTTA, 2005).

\section{5 - AS DIFICULDADES DE FINANCIAMENTO DOS PARQUES}

Os Parques Nacionais da América Latina são mantidos na maioria das vezes por orçamento público, essas áreas dependem exclusivamente dos recursos da União. Considerando os altos custos na criação, implantação e manejo das áreas protegidas, a receita obtida com arrecadação de ingressos, concessões e venda de produtos e subprodutos florestais, nos casos de florestas nacionais e reservas extrativas, são muito baixos e muitas vezes não se revertem diretamente para a instituição (MOTTA, 2005).

Existem, porém, diversos instrumentos de financiamento que podem ser utilizados para obter investimentos para as áreas protegidas. Conforme Van Schaik et al. (2002) existem financiamentos utilizando recursos do orçamento publico federal, estadual, privado, investimentos de instituições multilaterais e bilaterais como o Banco Mundial e outras agências. As organizações NãoGovernamentais têm uma importante atuação na captação de recursos, como forma de financiar projetos de conservação ambiental, dentro do qual o ecoturismo muitas vezes está inserido, buscando recursos via políticas públicas, pela contribuição de filiados, colaboradores, organismos internacionais e organizações de iniciativa privada.

Segundo Barifouse (2003 apud PIRES, 2004 p. 70) os parques brasileiros, assim como os demais ao redor do mundo enfrentam uma série de problemas, dentre eles os de questões administrativas e institucionais relacionadas à falta de financiamentos. No Brasil, por exemplo, em relação ao financiamento de 
unidades de conservação o gasto do IBAMA corresponde a 17\% de suas verbas, em média $\mathrm{R} \$ 170,00$ por $\mathrm{km}^{2}$.

"Em todas as fases de gestão, a maioria das áreas protegidas enfrenta dificuldades na obtenção de financiamentos e na administração adequada desses recursos. Em muitos casos, falta disposição e capacidade para administrar o apoio político, público e financeiro para a conservação das áreas protegidas. Os recursos financeiros advindos das fontes de financiamento são instáveis, ou seja, as UC's não podem contar sempre com esses financiamentos" (MORSELLO, 2001 apud MOTTA, 2005).

Isso ocorre, às vezes, porque as agências financiadoras questionam alguns gastos das UC's, como a compra de terras e o pagamento de funcionários. A falta de comprometimento e ineficiência na administração pode dificultar o manejo eficaz das áreas protegidas, e isso é particularmente importante, pois os recursos financeiros obtidos para serviços e projetos prestados pela UC's, devem ser elaborados por profissionais que visam a rentabilidade do Parque (MOTTA, 2005).

“Os órgãos responsáveis pela gestão UC's estão sempre limitados em seus recursos monetários. Na América do Sul, por exemplo, a maior parte dos países está passando por ajustes estruturais que limitam a capacidade de gastos e investimentos pelos governos, resultando em reduções orçamentárias massivas do setor publico. Esses problemas levam à necessidade de soluções inovadoras para o financiamento das áreas protegidas, que ampliem o leque atual de opções" (MORSELLO, p.139-140, 2001).

A restrição aos investimentos econômicos e sociais nas unidades é uma das causas dos conflitos entre a população local e os administradores das UCs. Isso ocorre devido aos recursos financeiros do Tesouro Nacional não serem divididos entre os interesses sociais da população e os de conservação das áreas protegidas (VAN SCHAIK \& RIJKSEN, 2002 apud MOTTA, 2005). Contudo é necessário especificar que a ausência de recursos financeiros muitas vezes não é o único problema enfrentado nas UC's. Na tabela 1, apresentada a seguir, serão abordados as principais dificuldades de sustentação das UC's. 


\begin{tabular}{|c|c|}
\hline \multicolumn{2}{|c|}{$\begin{array}{c}\text { Tabela } 1 \\
\text { Principais Dificuldades de Sustentação das Unidades de Conservação }\end{array}$} \\
\hline Principais Causas & Razões \\
\hline \multirow{3}{*}{$\begin{array}{l}\text { Apoio nacional fraco } \\
\text { para as áreas de } \\
\text { conservação }\end{array}$} & Consciência da sociedade quanto à importância das áreas protegidas \\
\hline & Conflitos com a população local \\
\hline & $\begin{array}{l}\text { Falta de envolvimento dos residentes locais na implantação desses } \\
\text { recursos }\end{array}$ \\
\hline \multirow{6}{*}{ Capacidade política } & Conflitos com populações residentes \\
\hline & Vontade Politica \\
\hline & Recursos financeiros insuficientes e não-seguros \\
\hline & Ausência de planos de Manejo \\
\hline & Ausência/precário de limites de fronteiras das áreas de preservação \\
\hline & Conflitos com outros órgão governamentais \\
\hline \multirow{4}{*}{$\begin{array}{l}\text { Capacidade } \\
\text { institucional }\end{array}$} & Carência de comunicação entre gestores ambientais \\
\hline & Capacidade institucional inadequada \\
\hline & Gestão limitada (meramente preservacionista) \\
\hline & Carência de uma equipe especializada \\
\hline \multicolumn{2}{|c|}{ Fonte: MOTTA (2005) apud DUDLEY e STOLTON (1999);SALGADO (2000); WWF (2000;2004) } \\
\hline
\end{tabular}

Conforme analisado, as dificuldades de sustentação das UCs dependem extremamente de recursos financeiros, pessoal, social e governamental para obter um desenvolvimento sustentável e eficaz para a preservação e conservação do meio ambiente, assim as linhas de créditos do financiamento poderiam fornecer subsídios a todas essas demandas. 


\title{
3. ECOTURISMO COMO ALTERNATIVA ECONÔMICA PARA GESTÃo DE PARQUES NACIONAIS
}

\author{
3.1 - ECOTURISMO: SUA IMPORTÂNCIA ECONÔMICA, SOCIAL, AMBIENTAL E \\ SUA RELAÇÃO COM O DESENVOLVIMENTO ECONOMICO E SOCIAL DE UM \\ PAÍS.
}

A atividade turística envolve diversos segmentos turísticos, um deles o ecoturismo. No Quênia, por exemplo, a segunda maior fonte de renda de origem externa do país vem do turismo ecológico; já, no Equador, no Parque Nacional das Ilhas Galápagos as rendas geradas pelo atendimento aos turistas contribuíram significativamente para a economia do país (MORSELLO, 2001). No entanto, mesmo essa fonte de renda financeira pode não ser suficiente para incentivar o governo a aumentar os recursos financeiros para as áreas protegidas.

A essência do ecoturismo encontra-se na natureza e nas atividades ao ar livre. O ecoturismo focaliza os aspectos físicos e biológicos do ambiente natural, a conservação e o manejo desses recursos como pré-requisitos básicos para o desenvolvimento da atividade (FERRETI, 2002). Busca valorizar as premissas ambientais, sociais, culturais e econômicas conhecidas de todos nós, e tem na interpretação do patrimônio natural e cultural um elemento indispensável na composição da experiência turística. Segundo PROECOTUR (2002),

\footnotetext{
"o Ecoturismo é um ramo do turismo que utiliza os recursos naturais e culturais de um determinado lugar e contribui para conservá-los. Busca desenvolver o respeito pela natureza por meio do contato com o ambiente natural e promove o bem-estar das populações locais envolvidas".
}

O ecoturismo surgiu com grande intensidade no final do século $X X$, e hoje é alvo de um grande número de pessoas, e particularmente sua prática tem sido bem significativa em países em desenvolvimento. A taxa de crescimento anual de $12,5 \%$ registrada para países não industrializados, se contrapõe aos 7\% 
indicados para países da Organization for Economic Cooperation end Developement - OECD (Organização de Cooperação Econômica de Desenvolvimento). Essas estatísticas contribuem para aumentar os incentivos do governo nesta área e fazer com que as organizações conservacionistas tenham mais força para levar a prática do ecoturismo aos paises subdesenvolvidos (VAN SCHAIK, 2002).

Estudos realizados pelo World Travel \& Tourism Council - WTTC (Conselho Mundial de Viagens e Turismo) demonstraram que cerca de 300 milhões de pessoas viajaram em 1999 em busca de belezas naturais. Atualmente uma em cada dez pessoas que viajam a passeio são ecoturistas. Por isso o ecoturismo é um tipo de turismo em rápida expansão, apresentando nos últimos dez anos uma taxa de crescimento de $7 \%$ ao ano (PROECOTUR, 2002).

Como atividade econômica, o turismo possui grande capacidade de gerar receitas nos núcleos receptores. O turismo interno, segundo informações da Fundação Instituto de Pesquisas Econômicas ( FIPE), gerou uma receita de $R$ \$31,9 bilhões, o equivalente a $3,5 \%$ do PIB nacional (Instituto Brasileiro de Turismo Embratur, 2000). Outro fator com grande relevância, é a propensão do segmento para a geração de empregos. Foi estimado que no Brasil o turismo empregou em torno de $9 \%$ da população economicamente ativa em 1997, ou seja, 6,7 milhões de empregos diretos e indiretos (CASIMIRO, F., 2002).

Com isso o turismo se transforma em uma maneira de gerar riquezas, dos países mais ricos para os mais pobres, pois muitos turistas estrangeiros exploram esses países em desenvolvimento, deixando milhares de dólares todos os anos. Em muitos destes países, o turismo é a principal fonte de renda, "pela geração de empregos, capacidade de gerar divisas, poder de promoção de crescimento regional e por oferecer alternativa a outras formas de desenvolvimento econômico, com isso o turismo se torna particularmente atraente aos governos como, por exemplo, a Costa Rica". (WEARING \& NEIL, 2001 apud PIRES, 2004, p. 38). De acordo com Lindberg et al. (2002, p. 33), 


\begin{abstract}
"especialistas em desenvolvimento rural estão pesquisando o potencial econômico do ecoturismo, os governos estão considerando esse potencial como fonte de entrada de divisas, escritórios de turismo estão começando a criar políticas para o ecoturismo e as agências de financiamento do setor privado estão avaliando a viabilidade financeira de investimento".
\end{abstract}

A importância do ecoturismo entre governos dos paises em desenvolvimento, as operadoras comerciais, as organizações assistenciais e os conservacionistas, demonstra a dimensão enorme de seu potencial econômico e de conservação (LINDBERG, 2002). O ecoturismo envolve bilhões de dólares todos os anos, tanto pelos gastos dos turistas quanto pelos investimentos necessários para a manutenção dessa atividade.

A Organização Mundial de Turismo - OMT (2003) enfatiza como de máxima consideração para o Ecoturismo, a conservação da natureza, a educação ambiental e as alternativas de conservação, tendendo desta forma, a atrair visitantes que respeitem o ambiente natural e as culturas locais, e que movimentem a economia local com o pagamento de serviços de hospedagem, receptividade, guiamento, taxas de preservação e ingressos nos atrativos, entre outros. A Interpretação ambiental, que tem o cunho educacional não formal, representa uma maneira atraente de disponibilizar a visitação adequada à preservação da natureza, buscando atender aos objetivos legais e contemplando contextos locais. Como metodologia, a Interpretação Ambiental reúne elementos capazes de conciliar a gestão de áreas protegidas, educação ambiental, recreação, e participação comunitária na preservação da natureza.

O ecoturismo oferece grandes possibilidades de desenvolvimento, mas também envolve riscos. Na tabela 2 a seguir, será feita uma comparação dos aspectos positivos e negativos do ecoturismo. 


\begin{tabular}{|c|c|}
\hline \multicolumn{2}{|c|}{$\begin{array}{c}\text { Tabela } 2 \\
\text { Aspectos Ambientais Positivos e Negativos do Ecoturismo }\end{array}$} \\
\hline \multicolumn{2}{|c|}{ ASPECTOS AMBIENTAIS } \\
\hline $\begin{array}{l}\text { Quando bem planejado e monitorado gera } \\
\text { diversos aspectos POSITIVOS }\end{array}$ & $\begin{array}{l}\text { Quando não ocorre o devido planejamento } \\
\text { e monitoramento pode ocorrer impactos } \\
\text { NEGATIVOS }\end{array}$ \\
\hline $\begin{array}{l}\text { Destina recursos financeiros para a conservação e } \\
\text { incentiva a recuperação de áreas degradadas }\end{array}$ & $\begin{array}{l}\text { Alterações nos comportamentos, hábitos } \\
\text { alimentares e na reprodução dos animais silvestres } \\
\text { pelo excesso de visitação e/ou presença de lixo. }\end{array}$ \\
\hline $\begin{array}{l}\text { Estimula levantamentos de fauna e flora e incentiva } \\
\text { a pesquisa científica }\end{array}$ & Mudanças numéricas nas populações silvestres \\
\hline $\begin{array}{l}\text { Promove a educação ambiental e maior } \\
\text { consciência ambiental nas populações }\end{array}$ & $\begin{array}{l}\text { Comércio ilegal de espécies silvestres e de } \\
\text { artesanatos que utilizem órgãos, penas ou couro de } \\
\text { animais }\end{array}$ \\
\hline Viabiliza tecnologias ambientalmente sustentáveis & Poluição do ar, água, solo,sonora e visual \\
\hline $\begin{array}{l}\text { Estimula a implantação de infra-estrutura } \\
\text { básica,saúde,comunicação,segurança,educação e } \\
\text { comercio }\end{array}$ & Abertura de estradas, trilhas e atalhos inadequados \\
\hline $\begin{array}{l}\text { Valoriza áreas naturais e condições de unir } \\
\text { desenvolvimento e conservação }\end{array}$ & Compactação e erosã \\
\hline $\begin{array}{l}\text { Estímulo a conservação, por convencer o governo e } \\
\text { o publico em geral da importância dessas áreas. }\end{array}$ & $\begin{array}{l}\text { Desrespeito à capacidade de carga dos } \\
\text { ecossistemas, gerando redução da qualidade da } \\
\text { visita e degradação do meio ambiente natural e } \\
\text { cultural }\end{array}$ \\
\hline \multicolumn{2}{|c|}{$\begin{array}{l}\text { Fonte: Turismo Verde/Programa de Desenvolvimento do Ecoturismo na Amazônia Legal - PROECOTUR, } \\
\text { 2002, p.22 e Kinker, 2002, p. 60-61. }\end{array}$} \\
\hline \multicolumn{2}{|c|}{$\begin{array}{c}\text { Tabela } 3 \\
\text { Aspectos Econômicos Positivos e Negativos do Ecoturismo }\end{array}$} \\
\hline \multicolumn{2}{|c|}{ ASPECTOS ECONÔMICOS } \\
\hline $\begin{array}{l}\text { Quando bem planejado e monitorado geram } \\
\text { diversos aspectos POSITIVOS }\end{array}$ & $\begin{array}{l}\text { Quando não ocorre o devido planejamento } \\
\text { e monitoramento podem ocorrer impactos } \\
\text { NEGATIVOS }\end{array}$ \\
\hline $\begin{array}{l}\text { Geração de emprego para população local, de } \\
\text { maneira direta e indireta, estimulando o } \\
\text { estabelecimento de indústrias domesticas de } \\
\text { artesanato e o oferecimento de serviços como } \\
\text { transporte, guias, etc. }\end{array}$ & Inflação \\
\hline $\begin{array}{l}\text { Diversificação da economia do local, } \\
\text { particularmente em áreas rurais, onde o emprego } \\
\text { na agricultura pode ser esporádico e insuficiente. }\end{array}$ & $\begin{array}{l}\text { Na baixa temporada muita gente pode ficar sem } \\
\text { emprego, as atividades dependem das estações do } \\
\text { ano (sazonalidade). }\end{array}$ \\
\hline $\begin{array}{l}\text { Fornece mecanismos de autofinanciamento que os } \\
\text { administradores usariam para a conservação da } \\
\text { natureza nessas áreas. }\end{array}$ & $\begin{array}{l}\text { Pode haver prejuízos econômicos como } \\
\text { conseqüência de boatos, problemas com doenças, } \\
\text { mudanças no setor financeiro, etc. }\end{array}$ \\
\hline Complementa outras atividades econômicas & $\begin{array}{l}\text { A economia pode ficar dependente do ecoturismo } \\
\text { como única fonte de renda }\end{array}$ \\
\hline $\begin{array}{l}\text { Fonte: Turismo Verde/Programa de Desenvolvime } \\
\text { 2002, p.22 e Kinker, 2002, p. 60-61. }\end{array}$ & o do Ecoturismo na Amazônia Legal - PROECOTUR, \\
\hline
\end{tabular}


Como foi observado nas tabelas 2 e 3 o ecoturismo pode tanto beneficiar quanto prejudicar o ambiente visitado. Segundo Kinker (2002, p. 25), é inevitável que a entrada de turistas em áreas naturais pouco visitadas pelo homem intervenha no meio ambiente, em razão das novas atividades e das novas facilidades. No entanto, a sua limitada capacidade de suportar pressões (lugares ecologicamente frágeis) faz com que a probabilidade de o ecoturismo causar impactos negativos seja grande. Assim, a impressão que se procura transmitir é que, por ser uma atividade que acontece na natureza e promove princípios ambientalistas, tem impacto insignificante no meio ambiente. Porém, se não for planejado, o ecoturismo pode gerar mais impactos do que qualquer outro segmento do turismo.

É imprescindível que ele seja planejado de forma a proporcionar o maior benefício ao turismo e o menor impacto sócio-ambiental. Este planejamento implica em estabelecer um plano de manejo em que o objetivo é controlar a interação homem/natureza, de modo que o meio ambiente não sofra impactos negativos e o turista tenha não só uma experiência agradável, mas seja levado, por meio da interpretação da natureza e do lazer dirigido, a incorporar mudanças de atitudes e comportamentos.

Como destacado anteriormente, o ecoturismo é hoje em dia uma fonte econômica alternativa para áreas protegidas, o lucro gerado pela demanda turística, cria uma fonte de renda, destinada à preservação dos recursos naturais, mas exige uso racional, com bases no desenvolvimento sustentável. Os dados apresentados não deixam dúvidas de que o ecoturismo está sendo uma grande fonte de renda para alguns paises. Conforme Lindberg (2002), um bom exemplo é o Quênia que arrecada cerca de 500 milhões de dólares por ano com o ecoturismo, e os seus lucros diretos e indiretos são responsáveis por cerca de $10 \%$ do produto nacional bruto. A renda gerada do turismo em áreas protegidas da África Oriental representa a maior fonte de rendimentos da região. O ecoturismo é atualmente uma fonte econômica alternativa. O lucro gerado pelos turistas é a grande fonte financiadora de ações que visam à preservação dos recursos naturais e seu uso racional, alem da geração de divisas, emprego e renda.

Para melhor contextualizar a influencia da atividade turística nos fatores econômicos de um país, abordaremos um estudo realizado no Brasil e na 
Itália para dimensionar o segmento do turismo nas relações econômicas e sociais de um país.

Será analisando a participação de algumas atividades na composição do produto interno bruto (PIB) e de pessoal ocupado no segmento turístico no Brasil. Para realização desse estudo foi utilizado o modelo de insumoproduto para economia turística brasileira, ano de 1999, apresentado por Casimiro Filho \& Guilhoto (2002).

Conforme SAAB, (1999 apud CASIMIRO \& GUILHOTO, 2002), o Brasil, mesmo tendo uma inexpressiva classificação no ranking dos países mais visitados no mundo, apresenta características naturais favoráveis para o desenvolvimento do turismo, porém o desempenho do segmento tem apresentado taxas inferiores ao resto do mundo, provavelmente devido a pouca importância dada a esta atividade até poucos anos atrás. Além disso, há também uma grande carência de infra-estrutura turística e de transporte, preços elevados, principalmente de passagens aéreas e um baixo nível de segurança para os turistas.

De acordo com o estudo analisado, no Brasil existem poucas pesquisas que quantificam, com maior rigor, a participação desse segmento na economia. Para os pesquisadores a falta de estudos dessa natureza é um dos entraves para o crescimento do turismo no país, uma vez que os formuladores de política e planejadores não dispõem de informações confiáveis sobre o referido segmento, dificultando, assim, a determinação de qual a melhor diretriz a ser adotada.

O estudo analisado em anexo denominado "Teoria do Jogos e Sustentabilidade do Desenvolvimento Turístico: A Função da Interação TuristaMorador", desenvolvido pelos pesquisadores Bimonte, S., Niglia, G. e Punzo,LF., na Itália em 2003, faz parte de uma inovadora e ampla pesquisa de sustentabilidade turística centralizada pelo projeto "Observatório para o Turismo Sustentável". Este estudo tem como foco principal a importância da observação do impacto da atividade turística em relação ao nível de bem estar dos moradores, em particular da capacidade local de lidar, de forma sustentável, com os recursos naturais essenciais ao processo de desenvolvimento turístico.

Bimonte et al (2003) ressaltam que o desenvolvimento turístico é reconhecido como um conjunto de atividades econômicas que contribuem para melhoria do bem estar da economia local. Reforçam a importância do 
desenvolvimento e da promoção do turismo para a geração de trabalho, oportunidade para o comércio, entrada de divisas, melhora da infra-estrutura local que, além de garantir um nível superior de serviços para a população local, possibilita investimentos em outros setores além do turístico. O conjunto de tais características confere ao fenômeno turístico uma legitimação política e social difundida tanto nos países desenvolvidos, quanto naqueles em via de desenvolvimento.

Segundo Bimonte et al. (2003), apesar dos efeitos positivos gerados pelo desenvolvimento turístico, os aspectos negativos, como agressão ao meio ambiente, centralização de dinheiro nas mãos de poucos, entre outros, requerem uma minuciosa observação do impacto da atividade turística em relação ao nível de bem estar dos moradores, em particular a capacidade local de lidar, de forma sustentável, com os recursos naturais essenciais ao processo de desenvolvimento turístico. O desenvolvimento turístico é geralmente justificado pelos benefícios econômicos que traz e ao mesmo tempo condenado pelos seus efeitos negativos em termos sociais, culturais e ambientais.

Outras pesquisas realizadas por Huang e Stewart (1996) observaram que o desenvolvimento turístico altera as relações entre os moradores. Existe um processo progressivo de deterioração social e ambiental que acontece em fases nas localidades turísticas. Primeiramente o território é descoberto por grupos restritos de turistas atraídos pela riqueza natural do lugar. Então se iniciam fatores externos e internos na localidade como, por exemplo, a baixa quantidade de turistas, que ocorre devido à dificuldade de acesso e pela escassez de serviços oferecidos. $A$ iniciativa privada então começa a intervir para satisfazer as exigências de um número mais elevado de turistas que começam a se sentir mais atraído pelo lugar. Em seguida a iniciativa privada local e internacional investe os próprios recursos para adaptar o lugar às preferências dos turistas (commoditization.) A população é induzida a oferecer ao turista o melhor, em troca de um lucro sempre maior, deixando de lado o impacto social e ambiental associado ao turismo. Em conseqüência se manifestará uma persistente diferença entre custos e benefícios sociais e privados (COPPER et al, 1993; SINCLAIR, 1991 apud BIMONTE, 2003).

Estudos revelam a reação negativa da população residente em compartilhar os recursos do território com os turistas, pois a iniciativa privada não leva em conta o custo da alteração dos equilíbrios ecológicos e que futuramente 
deverão ser pagos pela população local por instaurar um processo não sustentável de aproveitamento dos recursos naturais e culturais (FONT, 1995; SNAITH and HALEY, 1994 apud BIMONTE, 2003).

Todos os estudos citados concluem que a estratégia de mercado sem planejamento impede a realização do objetivo da sustentabilidade, por ignorar os impactos sociais e ambientais do processo de desenvolvimento. Esta constatação é a base para se estabelecer um processo de desenvolvimento capaz de minimizar o prejuízo social e ambiental. Fenômenos como a super lotação, ou uma mudança estrutural e social, onde os interesses da comunidade estão sujeitos a influencia dos investidores privados, provoca a deterioração da capacidade de atração do lugar.

A atividade turística, se não acompanhada de uma atenta estratégia política de preservação dos recursos naturais, pode desencadear um processo de deterioração dos mesmos recursos que constituem o principal instrumento para a obtenção dos níveis mais elevados de atração turística e bem estar social.

\section{2 - O PAPEL DO ECOTURISMO EM PARQUES NACIONAIS}

Segundo alguns estudos, o ecoturismo começou a se intensificar em áreas naturais a partir dos anos 60 , com o aumento da preocupação ambiental. 0 fluxo de turistas em áreas protegidas em todo mundo vem duplicando de ano a ano, estimulado pela mídia escrita e falada, que mostra sempre lugares paradisíacos e de natureza reservada (KINKER, 2002). Os turistas, como nunca antes, visitam parques e reservas em todo mundo, e encaram essa experiência como uma forma de conhecer e apreciar o meio ambiente natural (LINDBERG, 2002). Trata-se, portanto, de uma alternativa que pode ser explorada nos Parques Nacionais brasileiros, com vistas a fornecer renda suficiente à sua manutenção sustentada.

As áreas naturais possuem juntamente com sua paisagem natural, fauna e flora, todo um contexto cultural, com histórias e grandes atrações, tanto para os habitantes locais como para turistas do mundo inteiro. Por essa grande relevância e abundancia de atrativos naturais, as organizações para a conservação estão cientes dos inúmeros danos que um turismo mal administrado e sem controle pode provocar no patrimônio natural e cultural da localidade explorada. 
É de suma importância, para o sucesso da administração de um parque nacional, a participação das populações nativas, cujos antecedentes viveram ali por muitas gerações. Eles conhecem infinitamente melhor a área do que os administradores e servidores da unidade e podem colaborar para o desenvolvimento sustentável do local (LEUZINGER, 2002). Nas precisas palavras de Leuzinger, (2002, p.38),

"O parque nacional é muito mais que uma unidade de proteção integral (Lei $n^{\circ} 9.985$, de 2000 , art. $8^{\circ}$ e inc. III), é uma área sobre a qual convergem complexos interessantes e necessidades humanas, e que têm múltiplas funções: proteção ambiental, realização emocional, psicológica, espiritual e cultural do ser humano; área nativa, fonte de vida e local de veneração de populações tradicionais; alavanca de desenvolvimento sustentável de vastas regiões, geradora de emprego e renda; símbolo que agrega as pessoas, dando-Ihes maior consciência e orgulho de sua terra natal, de sua gente e de seu País".

Conforme citado acima, o princípio de equilíbrio tem que proporcionar o máximo de proteção ambiental com o mínimo de proibição. Porém isso não é bem o que acontece nos países em desenvolvimento, onde as proibições de práticas ecoturísticas se contrapõem com uso máximo e inadequado, de forma freqüente em Parques Nacionais.

O desenvolvimento da atividade turística em Parques e Reservas ambientais tem crescido também devido ao interesse dos turistas por regiões menos exploradas, que thes proporcione uma vivência mais direta com a natureza. A valorização de bens não apropriáveis como o ar puro, o mar, as belezas naturais, o contato com a natureza, é o resultado de um novo paradigma de vida da população dos grandes centros urbanos, que vêem na pratica do ecoturismo um estilo de vida mais natural.

O objetivo do ecoturismo em áreas protegidas é construir um instrumento legítimo para preservação do ecossistema e para a promoção do desenvolvimento sustentável. É difícil de avaliar ao certo o valor da conservação e do desenvolvimento sustentado do ecoturismo. As vantagens podem ser maximizadas e os riscos, diminuídos. Mas uma questão é certa, para que isto 
ocorra, é fundamental um bom planejamento, para ajudar os Parques a se prepararem para o turismo (LINDBERG, 2002).

O plano de manejo é a principal ferramenta para estabelecer e conduzir positivamente o ecoturismo em UCs. Os principais passos para o manejo do ecoturismo são:

- identificar as atividades possíveis e permitidas de serem realizadas naquele ambiente, com base no zoneamento definido no plano de manejo;

- criar métodos de monitoramento para minimizar os impactos de visitação e ter subsídios para adequar as diversas variáveis;

- constituir novas parcerias entre administradores de Parques, operadoras de turismo, comunidade local e governo;

- estabelecer ferramentas autofinanciáveis como concessões de serviços que devem ser fiscalizados pelo órgão responsável pela UCs;

- desenvolver pesquisas da demanda e oferta do atrativo e da localidade, com estatísticas do numero de visitantes durante 0 ano, para detectar sazonalidade, pesquisas sobre o perfil do turista,seus anseios e motivações, a qualidade do serviço, dentre inúmeras outras estatísticas que podem ajudar o planejamento da unidade (KINKER, 2002).

È de suma importância para a pratica do ecoturismo em Parques Nacionais desenvolver os recursos necessários para atender a demanda do mesmo. Uma infra-estrutura adequada e acolhedora é fundamental para receber o turista, como uma boa recepção, apropriada para facilitar a interpretação, com painéis explicativos, informações básicas do local, funcionários treinados e as instalações mínimas necessárias, como banheiros, bebedouros, cozinha e guarita. Proporcionando assim, um grau de auto-suficiência funcional e melhoria na qualidade da experiência do visitante.

Outro recurso importante são os estudos referentes à capacidade de carga, desenvolvido para dimensionar o impacto dos visitantes nos recursos naturais, culturais, na comunidade receptora e até na qualidade da experiência vivida e da satisfação do visitante.

Outra questão fundamental de gestão para o ecoturismo é o controle e o planejamento da visitação em áreas protegidas, inseridas no Sistema Nacional de Unidades de Conservação da Natureza (MMA (2000), SNUC, Lei n.ำ 9.985, de 18 de julho de 2000). A visitação em Parques Nacionais pode ser compreendida como 
a atividades educativa, recreativa e de interpretação ambiental, que propiciam ao visitante a oportunidade de conhecer, entender e valorizar os recursos naturais e os recursos culturais dessas áreas. Conforme MMA - Diagnostico de Visitação de Parques Nacionais e Estaduais realizado pelo IBAMA, (2004, p.6),

"Nos últimos anos, observações empíricas indicam que as atividades em contato com os ambientes naturais têm aumentado tanto com relação às modalidades como em relação ao número de praticantes. Esta realidade tem demandado o estabelecimento de diretrizes e normas para que a visitação seja realizada de maneira adequada, respeitando um dos principais objetivos das áreas protegidas: a conservação da natureza. Uma das etapas necessárias no processo de elaboração destas diretrizes consiste em entender e diagnosticar a situação atual das atividades de visitação nas Unidades de Conservação (UC)".

No próximo capítulo serão discutidas atividades de visitação e outras ferramentas de gestão para o desenvolvimento sustentável do ecoturismo em Parques Nacionais. 


\section{INSTRUMENTOS DE GESTÃO PARA O ECOTURISMO EM PARQUES NACIONAIS}

\subsection{INSTRUMENTOS DE GESTÃO RELATIVOS À VISITAÇÃO E CONSERVAÇÃO}

O ecoturismo é um dos segmentos do turismo que mais cresceu nos últimos anos. No entanto, estudiosos acreditam que o segmento ainda não atingiu sua potencialidade como instrumento econômico, em parte porque os países e instituições hospedeiras não recebem o seu potencial de receita integral inerente ao ecoturismo. Apenas uma pequena parcela da receita gerada reverte diretamente para a conservação e desenvolvimento econômico do local. Outro fator importante é a falta de financiamento em projetos para desenvolver o ecoturismo e expandir a sua contribuição para a economia do país.

Hoje, entretanto, as grandes demandas por recursos naturais e serviços gerados do ecoturismo, quando não planejados, propiciam cada vez mais oportunidades para um descontrole nessas áreas, causando devastação e degradação do meio ambiente. Apesar da popularidade crescente entre os turistas, as oportunidades de ecoturismo nas áreas protegidas raramente são taxadas e controladas adequadamente. Parques, em todo o mundo, principalmente nos paises em desenvolvimento, cobram taxas pequenas ou não cobram pelo lazer que oferecem ao público. Nesse contexto, é imprescindível que os sistemas de áreas protegidas subsidiem de forma controlada oportunidades recreativas para turistas, gerando uma auto-sustentação.

As UC's necessitam de um plano de manejo ativo para o desenvolvimento sustentável do ecoturismo. Para isso exigem-se recursos monetários, e essa necessidade representa um dos principais problemas de conservação e gestão de áreas protegidas. Essa condição é responsável pela existência de muitas áreas protegidas instituídas legalmente "parques de papel", que não são submetidas a manejo (MORSELLO, 2001). Por estes fatos, tem se procurado alternativas inovadoras para a viabilização econômica das UC's. 
A geração de renda pelo ecoturismo justifica muitas vezes para o governo a alocação de verbas para a conservação da natureza, pois a pressão para maximizar a renda gerada por suas terras é suprida pelo valor oriundo dos ingressos representados pelo turismo. Esse retorno econômico por meio dos Parques torna-os mais atrativos para o governo (SPERGEL, 2002).

Será identificado neste capitulo também o valor do ecoturismo para os Parques Nacionais e o seu papel no contexto do manejo de uma área protegida. O potencial de desenvolvimento do ecoturismo pode ser exemplificado por meio de ferramentas de manejo que auxiliam na gestão e no planejamento sustentável do ecoturismo.

Uma das formas de planejamento para obtenção de recursos monetários que será abordado neste estudo é o autofinanciamento, considerado por alguns autores como imprescindível à sobrevivência das áreas protegidas. As diferentes variedades de autofinanciamento proveniente do ecoturismo decorrem da cobrança de taxas, ingressos, concessões de atividade, como bares, pousadas, camping, licenças de pesquisa, impostos à conservação dentre outros mecanismos, detalhados mais adiante.

Em países em desenvolvimento o autofinanciamento é muito importante, pois a filosofia usual de repartição de recursos governamentais comuns é totalmente ineficaz, já que a atividade conservacionista não compete com problemas imediatos como a falta de renda, emprego, educação e saúde (MORSELLO, 2001).

Há um número relativamente simples de mecanismos orientados pelo mercado para gerar receitas para a conservação do turismo (ver tabela 4). Em geral, a receita proveniente dessas atividades pode ser descrita pelas categorias de cobrança, a seguir: 


\begin{tabular}{|c|c|}
\hline \multicolumn{2}{|c|}{$\begin{array}{c}\text { Tabela } 4 \\
\text { Tipos de Taxas e Encargos em Áreas Protegidas }\end{array}$} \\
\hline Tipo de Taxa & Descrição \\
\hline Taxa de entrada & Permite o acesso a pontos além do portão de entrada \\
\hline Taxa de admissão & $\begin{array}{l}\text { Cobrado pela utilização de uma instalação ou atividade específica, por } \\
\text { exemplo: um museu ou uma aula de fotografia. }\end{array}$ \\
\hline Taxa de usuário & $\begin{array}{l}\text { Taxas pagas por visitantes para utilizar as instalações dentro da área } \\
\text { protegida, por exemplo: estacionamento, camping, centro de visitantes, uso } \\
\text { de barco, abrigos, etc. }\end{array}$ \\
\hline Licenças e autorizações & $\begin{array}{l}\text { Permite que firmas de turismo privado operem dentro de uma área } \\
\text { protegida, por exemplo: operadoras de turismo, guias, empresas de } \\
\text { transporte e outros usuários. }\end{array}$ \\
\hline "Royalty" e receita de vendas & Dinheiro proveniente da venda de suvenires \\
\hline Impostos & Por exemplo: sobre quartos do hotel, uso do aeroporto e de veículos. \\
\hline $\begin{array}{l}\text { Arrendamento e taxas de } \\
\text { aluguel }\end{array}$ & $\begin{array}{l}\text { Cobrança de aluguel ou arrendamento de propriedades do parque ou de } \\
\text { equipamentos. }\end{array}$ \\
\hline Doações voluntárias & $\begin{array}{l}\text { Incluem dinheiro, presentes e trabalho "em espécie" normalmente recebida } \\
\text { de grupos de "amigos do parque". }\end{array}$ \\
\hline Fonte: Drun & \\
\hline
\end{tabular}

Porém uma característica importante a ser ressaltada às formas de autofinanciamento, é que os lucros alcançados por uma UC na maioria das vezes não ficam no próprio sistema de áreas protegidas, e sim retornam para o caixa único do Tesouro, via IBAMA (MORSELLO, 2001).

Uma das principais ferramentas de taxação em Parques citadas acima são as "taxas de usuários". Trata-se de arrecadações coletadas de pessoas que utilizam as áreas protegidas, como taxas de entrada, pesca, caça, mergulho, caminhadas, escalada, canoagem, acampamento, fotografia e pesquisa cientifica. Conforme Lindberg (2002, p.144-145) 
"os administradores de áreas protegidas têm recorrido às taxas turísticas como um mecanismo para cobrir os custos de administração do visitante, bem como os custos de estratégias tradicionais de conservação ou dos programas de desenvolvimento da comunidade".

Neste capítulo serão abordadas ferramentas de taxação para visitantes, iniciando-se pelas taxas de entrada diferenciadas para visitantes estrangeiros. Essa fixação diferencial de preços é uma estratégia freqüente e relativamente direta para maximizar o beneficio econômico do país hospedeiro. As taxas mais baixas para os residentes no país devem ser incentivadas, pois promovem educação ambiental e recreação para a comunidade e incentiva a visitação da população local, de forma que esta população já paga impostos para a conservação da área protegida. Diante da pesquisa analisada foi evidenciado que geralmente os turistas estrangeiros estão pré-dispostos a pagar entradas mais altas para visitar áreas protegidas que possuem ecossistemas exclusivos (SPERGEL, 2002).

No Brasil a cobrança de ingressos muitas vezes é inexistente, em parte porque a entrada em grande parte das Unidades depende do pedido de uma autorização previa do IBAMA Central, dificultando a visitação. De outra, parte, em virtude das péssimas condições das acomodações e infra-estrutura, da falta de capacitação dos funcionários para auxiliar os visitantes e, por fim, o desestimulo a cobrança, já que os recursos adquiridos com o mesmo não retornam diretamente para a unidade (MORSELLO, 2001).

Adiante serão especificadas as categorias utilizadas para a arrecadação de taxas de entrada diferenciadas, em vigor, no parque Nacional de Galápagos, no Equador. Neste caso especifico as taxas são diferenciadas em muitas categorias, a fim de oferecer preços mais baixos aos países vizinhos da Unidade. 


\begin{tabular}{|lr|}
\hline \multicolumn{2}{|c|}{ Tabela 5 } \\
\hline \multicolumn{2}{|c|}{ Taxas de Entrada do Parque Nacional de Galápagos, no Equador } \\
\hline Categoria & $\underline{\text { US\$ }}$ \\
Turista estrangeiro (não-residente) & 100 \\
Turista estrangeiro com menos de 12 anos & 50 \\
Turista estrangeiro de um país membro da Comunidade Andina-MCA ou do Mercosur & 50 \\
Turista estrangeiro de um país MCA ou do Mercosur com menos de 12 anos & 25 \\
Cidadão equatoriano ou residente & 6 \\
Cidadão equatoriano ou residente com menos de 12 anos & 3 \\
Turista estrangeiro não-residente que freqüente uma instituição acadêmica nac. & 25 \\
Crianças equatorianas ou estrangeiras com menos de 2 anos & Não paga \\
Fonte: Governo do Equador, 1998 apud Drumm e Moore, 2003 & \\
\hline
\end{tabular}

Como alternativa para o Brasil e países em desenvolvimento a fixação de taxas referidas à visitação devem atingir dois objetivos possíveis: o primeiro é cobrir os custos do fornecimento do serviço (compensações de custos) e o segundo é a maximização de lucros, estipulando taxas, de modo que elas gerem o maior lucro possível, e ultrapasse os custos do fornecimento da atração turística (LINDBERG, 2002).

Geralmente, a finalidade de se cobrar uma taxa de entrada é aumentar os recursos disponíveis para a manutenção e o desenvolvimento da Unidade e da atividade ecoturistíca. Entretanto, o valor da taxa de entrada pode ser também um mecanismo para facilitar ou limitar o acesso de visitantes, dependendo da situação específica do PN. Se a administração desejar limitar a visitação devido ao seu impacto negativo, uma forma de alcançar esse objetivo é aumentar a taxa de entrada. Entretanto, apenas elevar ou diminuir essa taxa nem sempre tem um impacto direto sobre o número de visitantes. Pode também trazer conseqüências involuntárias, especialmente se o valor da taxa não for definido com base na demanda.

Um mecanismo muito importante para atingir a sustentabilidade econômica, utilizada em PN, são as taxas de concessão, que possibilitam que terceiros ofereçam serviços aos visitantes dentro de um sítio de ecoturismo. Os 
exemplos mais comuns são fornecer serviços de acomodação, alimentação aos visitantes, excursões com guias especializados, transporte em jipes, barcos e outros meios. Em alguns PN, a administração pode tomar a decisão de ela própria oferecer todos esses serviços sem envolver concessões. Por outro lado, a maior parte dos gestores dos sítios ecoturísticos não possui nem o conhecimento específico na área de turismo, nem o capital de investimento necessário para fornecer esses serviços de uma maneira profissional. De qualquer maneira, é necessária uma contabilidade estruturada e que passe por auditorias constantes, para que se possa utilizar dessa opção de forma controlada e sustentada.

Usualmente, a seleção das concessionárias é executada por meio de um processo de licitação, no qual a administração do PN desenvolve os termos do contrato e as partes interessadas oferecem seus serviços, incluindo o valor que querem pagar pela oportunidade de oferecer seus serviços. Quando as áreas protegidas são geridas pelo governo, esse processo pode ser demorado e complicado. Essa é uma maneira excelente de envolver a população local, como proprietária das concessões, ou como parceiras das concessionárias oferecendo seus serviços. Uma concessão pode ser uma alternativa viável para alguns sítios, especialmente se há uma grande demanda pelo serviço, desde que se priorize a necessidade de estruturar a área de forma sustentável.

Contudo, para que um desses objetivos de gestão se concretize, exige-se a existência de um número suficiente de turistas dispostos a pagar taxas altas para que se possam alcançar os objetivos. Para isso, as UC's devem ter um estudo de demanda para as suas atividades, como ecoturismo, pesquisas, turismo de aventura e outros que influenciam a quantidade demandada pela área protegida. $\mathrm{Na}$ Costa Rica, por exemplo, uma pesquisa realizada com os turistas costariquenhos e turistas estrangeiros, mostra que ambos concordavam que os preços dos ingressos dos três Parques Nacionais mais populares deveriam ser mais elevados (LINDBERG, 2002).

Os dados apresentados no Gráfico 1 demonstram que existe uma pretensão dos turistas tanto nacionais com estrangeiros em pagar mais para a conservação e preservação dos recursos naturais oferecidos pela área protegida. 


\section{Gráfico 1}

Preços de ingressos adequados para estrangeiros: opiniões colhidas em três parques da Costa Rica.

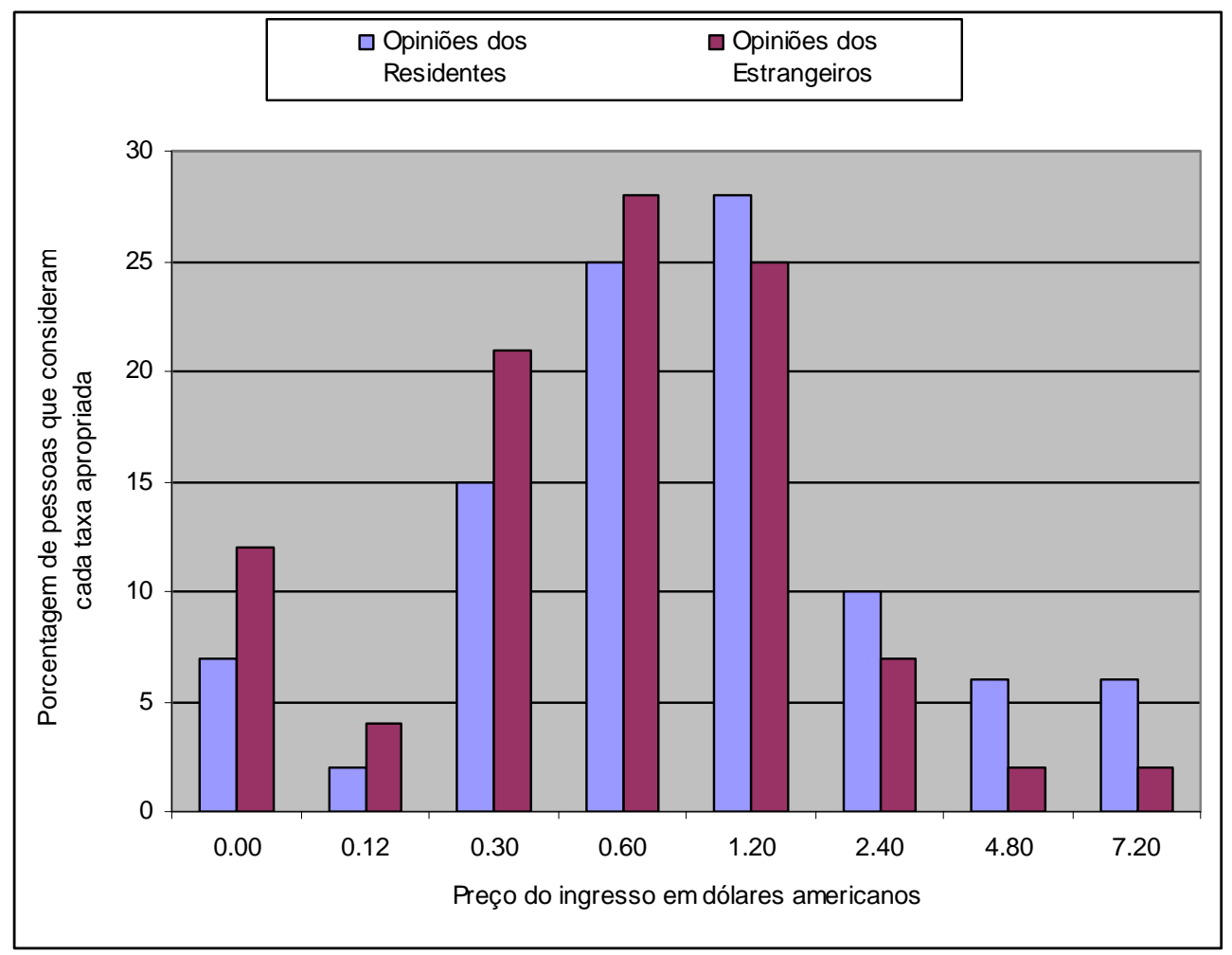

Fonte: Lindberg, 2002. Ecoturismo: guia para planejamento e gestão. p.154.

O Gráfico 1, proveniente de um trabalho de pesquisa com turistas na Costa Rica, sugere que uma taxa de aproximadamente US\$1,20 deve ser cobrado dos estrangeiros. Porém este método de pesquisa pode subestimar a demanda real, e conseqüentemente o nível potencial da taxa, pois quase sempre os turistas subestimam o que realmente estariam dispostos a pagar.

Outro método para estimar a demanda é por meio da análise da curva da demanda. Ela mede quanto os turistas estão dispostos a pagar(DAP) para visitar o atrativo, bem como estipula o preço e o número de visitantes identificados por concordarem com as taxas que promovam a maximização de receita. Utilizando esse método podemos fazer uma análise estatística simples para estimar a taxa de maximização da receita. No caso de Costa Rica a taxa foi estimada em US\$1,20, essa estimativa é considerada baixa para alcançar os objetivos de maximização de lucros e cobertura dos custos. As taxas provenientes do turismo podem gerar financiamento para o ecoturismo e programas de conservação, mas precisam ser 
estruturadas pelo método de análise custo-beneficio(ACB), ou seja, os benefícios excedem o valor dos custos, produzindo benefícios líquidos positivos (LINDBERG, 2002).

Para que o método se potencialize, a UC deve declarar formalmente ao órgão administrativo de Parques que uma porcentagem dessa verba arrecadada através das taxas possa nele permanecer, para cobrir seus custos e gerar benefícios. A idéia é que uma área protegida mantenha uma porcentagem fixa das taxas de entrada coletadas. Essa é uma sugestão que já possui exemplos reais, como o Nepal, que adotou em 1997 e o método do National Park Service dos EUA, onde os quatros Parques mais famosos - Yellowstone, Grand Teton, Yosemite e Grand Canyon são autorizados a manter $80 \%$ do total de taxas que coleta (SPERGEL, 2002). Assim, com os recursos advindos do ecoturismo em áreas naturais, o país conseguiu estruturar a atividade turística com uma infra-estrutura adequada e segura, gerou recursos para alocação de mão-de-obra especializada e local, para uma melhor manutenção e conservação dos Parques.

A primeira ferramenta recomendada ao se iniciar o turismo em uma área protegida é a estruturação de um sistema de zoneamento para implementar e executar a atividade turística, voltada para a determinação do melhor uso dos recursos naturais. Os parques necessitam de um sistema pró-ativo necessário para garantir a alta qualidade dos habitats naturais, limitando o acesso de turistas a ecossistemas frágeis e as zonas de conservação, mantendo um melhor balanço entre o acesso do visitante e a necessidade biológica. Quanto antes as autoridades encarregadas dos parques execute os planos de zoneamento, melhor será a determinação do melhor uso e investimento para cada área.

A implementação do plano de zoneamento pode ter restrições de acesso em níveis alto, médio e baixo, porém deve sempre propiciar uma variedades de experiências. Alguns visitantes buscam uma boa infra-estrutura, maiores acessibilidade aos atrativos, já outros procuram atividades mais selvagens, com trilhas primitivas, emoção, etc. Essas duas categorias de experiências proporcionadas pelo ecoturismo em áreas protegidas podem se designar a uma atividade extensiva ou intensiva, determinada pelo zoneamento e infra-estrutura adequada. 
" os parques que integram conscientemente zonas de conservação que proporcionam experiências variadas aos visitantes irão atrair um espectro mais amplo de turistas, mantendo a proteção da biodiversidade compatível com a visitação (DAVENPORT, 2002, p. 317)".

Limites Aceitáveis de Câmbio, o LAC, é outra ferramenta de gestão para o ecoturismo que emprega também uma forma de zoneamento, delineando zonas distintas como diferentes classes de oportunidades para o visitante e desenvolvendo indicadores de monitoramento sugeridos pelos objetivos do parque, tais como a freqüência de encontros com outros visitantes, a quantidade de compactação nas trilhas, qualidade na água, esmagamento da vegetação no entorno das áreas de acampamento,abundancia de espécies sensíveis e quantidade de lixo encontrada ( DAVENPORT,2002). Esta ferramenta ressalta a necessidade do monitoramento de impactos dos visitantes e de uma metodologia apropriada para o manejo do ecoturismo.

Este modelo de planejamento para o manejo do impacto gerado de pelos visitantes, desenvolvido nos Estados Unidos pelo National Park Service (NPS ) e o Serviço Florestal Americano é o LAC: Limite Aceitável de Mudança, que tem como um de seus mais importantes princípios, que o uso recreativo, seja a fonte fundamental da mudança nas condições sociais e ecológicas, mas preocupando-se com as condições desejadas e com quanto de mudanças pode ser tolerada em diferentes zonas de uso, admitindo que o real interesse é o efeito do uso e não quanto uso está ocorrendo (KINKER, 2002).

De acordo com Davenport, (2002) o gráfico a seguir demonstra uma metodologia para tomadas de decisão em áreas silvestres de acordo com LAC. 


\section{Figura 1}

O Sistema de Limites Aceitáveis de Câmbio (LAC) no Planejamento de Áreas Silvestres.

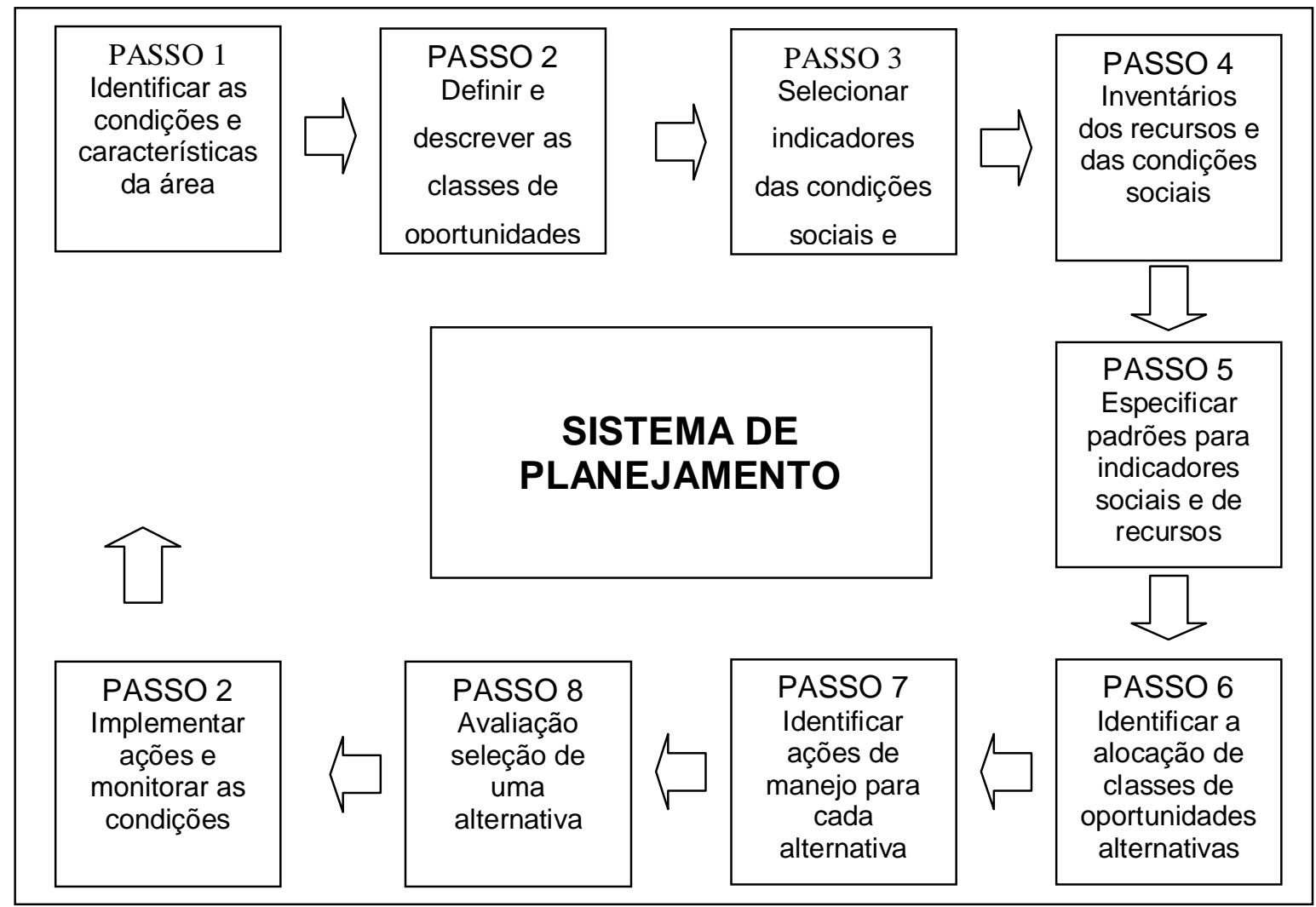

Fonte: Stankey et al, 1985 apud Davenport, L. 2002.

De acordo com Davenport, 2002 esta metodologia LAC tem sido proposta como alternativa para métodos de capacidade de carga no monitoramento e na mitigação de danos aos recursos naturais dos parques. Em vez de perguntar qual "qual é o uso máximo?", a metodologia LAC pergunta, "que condições naturais são desejáveis aqui?". O LAC emprega uma forma de zoneamento, delineando zonas distintas como diferentes classes de oportunidades para o visitante. Assim cada área do parque considerada com condições desejadas, os recursos são inventariados e são escolhidos indicadores de monitoramento. Os indicadores podem incluir fatores bióticos e abióticos sugeridos pelo objetivo do parque e pelas taxas de visitação. Os principais indicadores analisados são freqüência de encontros com outros visitantes;quantidade de erosão ou compactação nas trilhas;qualidade na água; quantidade de lixo encontrado; abundancia de espécies sensíveis, dentre outras. 
Figura 2

Processo de Planejamento de Manejo de Impactos Visíveis

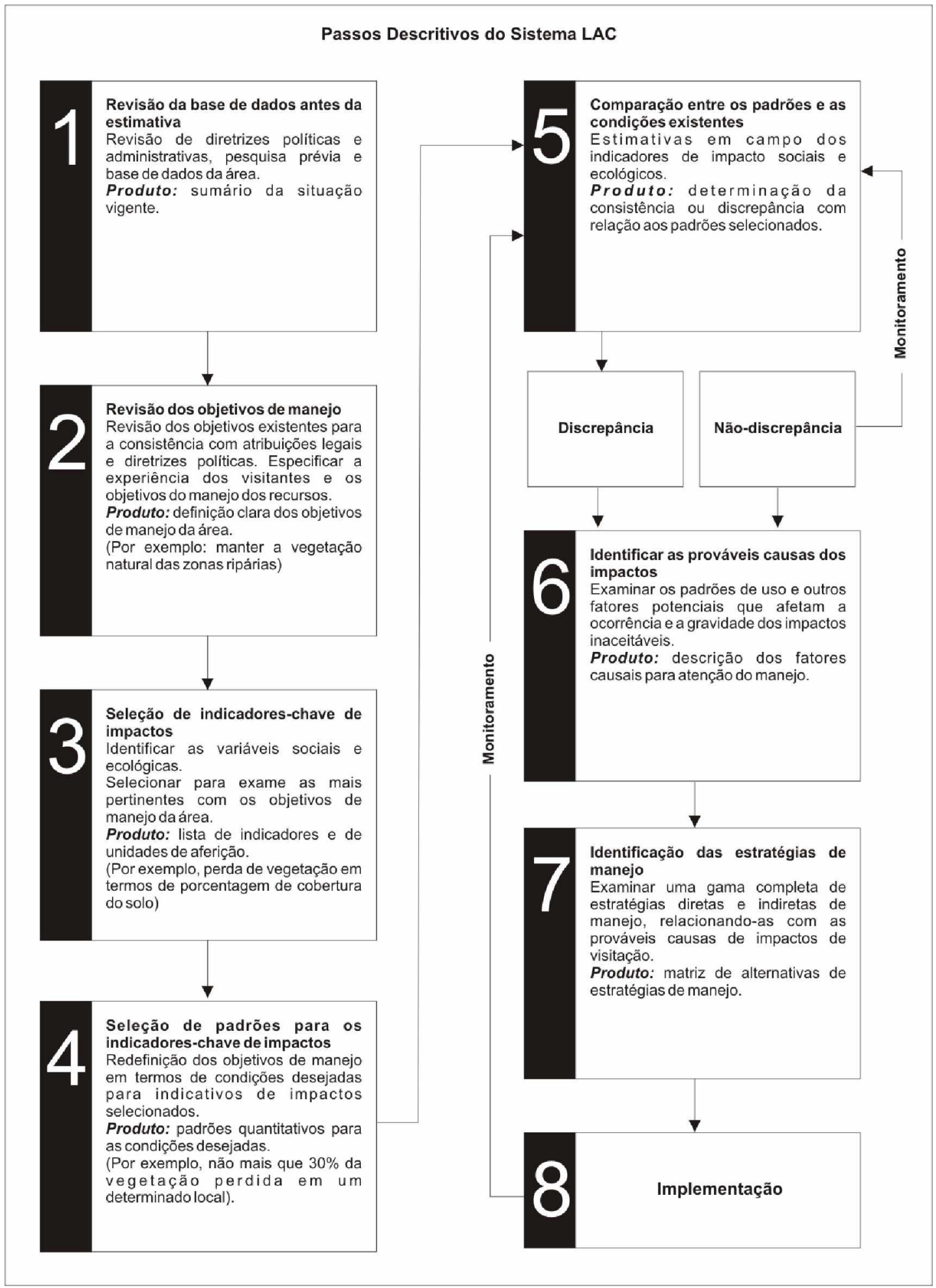

Fonte: Graef et al., 1990 apud Davenport, L. 2002. 